\title{
Give me five! - reasons for two-way communication between experts and citizens in relation to air pollution risk
}

\author{
Maria Loroño-Leturiondo ${ }^{1}$, Paul O'Hare ${ }^{1}$, Simon $\operatorname{Cook}^{2}$, Stephen R. Hoon ${ }^{1}$, and Sam Illingworth ${ }^{1}$ \\ ${ }^{1}$ Science and the Environment, Manchester Metropolitan University, Manchester, M1 5GD, England, UK \\ ${ }^{2}$ Geography, School of Social Sciences, University of Dundee, Dundee, DD1 4HN, Scotland, UK
}

Correspondence: Maria Loroño-Leturiondo (maria.lorono@stu.mmu.ac.uk)

Received: 13 February 2018 - Accepted: 20 April 2018 - Published: 27 April 2018

\begin{abstract}
Air pollution is a major environmental concern for many populations worldwide. Communication efforts so far have been based on a one-way provision of evidence and information from experts to society, and have arguably failed in their mission to foster a more aware and engaged society, or to result in cleaner air. Globally we are facing both an air quality crisis and a communication emergency. This paper focuses on the communication of air pollution risk, from the threats it poses (e.g. severe impacts to human health) to the opportunities it can create (e.g. behavioural or technological alternatives that lead to cleaner air). It supports the case for moving away from one-way communication, and identifies five key benefits of a practical two-way communication between experts and citizens in order to engender positive change and improve global air quality.
\end{abstract}

\section{Introduction}

According to the World Health Organization (WHO), $92 \%$ of the world's population live in places that exceed the recommended annual mean concentrations of $\mathrm{PM}_{2.5}\left(10 \mu \mathrm{g} \mathrm{\textrm {m } ^ { 3 }}\right.$ as established by WHO; WHO, 2016). This exposure has been linked to cancer, asthma, stroke and heart disease, diabetes, obesity, and dementia, and it is causing about 3 million deaths per year globally (WHO, 2016). Air pollution, however, is a constant and silent threat, that is not easily grasped without the help of visual or olfactory cues, such as smoke emanating from factories, car congestion in main roads within an urban centre, or an uncomfortable odour when standing next to a running car (Bickerstaff and Walker, 2001). This strong human component, where the citizen is "both a source and a victim" (Xu et al., 2017, p. 2), turns air pollution into a social issue, not just a scientific one. On the one hand, citizens need to understand the effects of air pollution on human health, as well as when and how to follow protective behaviours. On the other hand, citizens need to be aware of their contribution to air pollution and the mitigating behaviours already available to them, so that they can participate in the co-design of new alternatives that lead to- wards cleaner air. The severity of the threat that air pollution is posing worldwide, together with inaction and lack of engagement, can be described as a "communication emergency" (Priest, 2016). It appears then, that communication is key in bringing society up to speed with the problem that air pollution is posing worldwide. This paper is concerned with communication of the threats and opportunities of air pollution risk (conforming with the definition of risk stablished by ISO 31000:2018, a set of principles and guidelines for risk management codified by the International Organization for Standardization); it reflects on the need to move away from one-way provision of information from experts to society and towards two-way dialogue, and stablishes five benefits to be gained from this dialogical approach, identifying it as a vehicle for communicating awareness and facilitating change.

\section{The case for moving away from a one-way provision of information}

Communication in relation to air pollution has, until now, mainly been following the "deficit" model (Bickerstaff, 2004). This model adopts a "one-way, top-down communication process", through which scientists fill "the knowledge 
vacuum in the scientifically illiterate general public" with the information they believe to be relevant (Miller, 2001, p. 116). A one-way approach to communication, however, is unlikely to bring about the change needed to tackle air pollution, because it fails to consider a series of factors that are key determinants of the way people perceive and react to information.

The amount of information required to relate to a topic in a meaningful way varies from one individual to another. People rarely seek "all the science available"; rather, they want "enough" as to be able to "make up their minds about an issue" (Priest, 2016, p. 5). Sufficient information for one individual will not be enough for another, and information that exceeds or does not reach this threshold is unlikely to be effective. In other words, there is not a one-size-fits-all package of information able to engage society as a whole in regards to cleaner air. In addition to the amount of information individuals need, the way this information is presented will also have an impact on how it is perceived and taken on board. The complexity of the topic, the technicality of the information, and the framing of the message have all been proven to influence the successfulness of communication, and these too are subject to individual differences (Bickerstaff, 2004; Burningham et al., 2008; Cacciatore et al., 2016).

Indeed, even if a message sent through one-way communication had "enough" amount of information, the appropriate amount of complexity and jargon, and was framed in a suitable way, it would still ignore "the significant role of the environment and the individual as critical determinants of that information's use" (Longnecker, 2016, p. 4). Individuals are not passive receivers of information, ready to absorb and act upon the information received; they have beliefs, values, needs, and previous experiences that will influence, not only the way the information is processed, but also the consequent action (or inaction) it triggers (Harre, 2011; Longnecker, 2016). Together with the individual, the environment in which individuals are embedded is also a critical determinant of how information is acted upon (Longnecker, 2016). The norms that govern communities, as well as what others think, have proven to influence an individual's behaviour (Cacciatore et al., 2016; Longnecker, 2016; Priest, 2016), and information that does not fit or goes against these external factors is consequently likely to be discarded.

The source of the information is another factor that influences how it is perceived and assessed (Rogers, 2003). "It is not just the message but the messenger, then, that matters" (Priest, 2016, p. 56), and lack of trust in a source, such as the government, the media, or scientists, has proven to affect responsiveness to the message (Bickerstaff, 2004; Bultitude, 2011; Goodwin and Dahlstrom, 2014). Mere provision of evidence and information by a source perceived to be untrustworthy is unlikely to be effective. For instance, a lack of trust in the government can affect how people perceive policies in relation to climate change (Priest, 2016), or air pollution.
Finally, people reject information that goes against deeply held beliefs or that completely challenges their own lifestyles - a tendency known as "cognitive dissonance" (Festinger, 1962; Lorenzoni et al., 2007; Priest, 2016). The fact that one's lifestyle is actually a root cause of air pollution, and consequently one has to modify established behaviours, is not easily accepted. Although individuals might not necessarily deny their contribution to air pollution, they are likely to take refuge in day-to-day obligations and priorities. Merely providing evidence is, therefore, unlikely to overcome this issue (Priest, 2016).

\section{The case for two-way communication}

Two-way communication involves two or more "communicators" who both send and receive information (Bowater and Yeoman, 2012), moving away from the linear model of communication comprising the figures of a "sender" and a "receiver" (Shannon and Weaver, 1998). In contrast to the "deficit" model, the "dialogue" model highlights that "while scientists may have scientific facts at their disposal, the members of the public concerned have local knowledge and an understanding of, and personal interest in, the problems to be solved" (Miller, 2001, p. 117). It highlights the need to explore the identities and social norms of different groups in society, as well as the importance of acknowledging the existence of "many publics", in contrast to what the old model referred to as "the public"(Priest, 2016). Here we present five key benefits of two-way communication between the public and experts in relation to air pollution risk. These benefits will increase the likelihood of engendering positive change whether this is tied to mitigation and adaptation behaviours in the polluter, or protective behaviours in those suffering from pollution - and improving global air quality.

Firstly, two-way communication can improve technology and policy development in relation to air pollution. Tackling the issue of air pollution involves the development of new technology (such as hydrogen fuel cells or electric cars) for which societal acceptance is needed at the development and regulatory phases (Wilsdon and Willis, 2004). Similarly, new policy solutions are needed that can drive societies towards cleaner air, for which citizen involvement would be translated into better and more robust policy and funding decisions. The "Australian Climate Policy Forum", for example, composed of experts and twenty four citizens holding different views about carbon pricing, was created to evaluate the current governments' efforts and future directions of the emissions mitigation strategy, where citizens were invited to "jointly articulate criteria for a preferred carbon pricing policy" (Lo et al., 2013, p. 7). Although at the start of the forum there was a lack of consensus, the group agreed to support the notion of a carbon tax, as long as the implementation would rest on trusted and transparent administrative mechanisms. The key for finding consensus was to overcome trust 
issues in relation to the collection and management of the funds collected in the case of the implementation of a carbon tax (Lo et al., 2013). In a different forum in Kenya, the discussion evolved around measurements to reduce air pollution at the individual and community level. As a result, the group proposed a series of well-defined actions that the government could take, such as removing old vehicles that were not properly maintained from the roads, due to their significant contribution to the air pollution problem ( $\mathrm{Ngo}$ et al., 2017).

Secondly, beyond exploring individuals' needs and aspirations in relation to policy and scientific or technological developments, two-way communication can easily gather additional data on air pollution. Citizen science initiatives, which are gaining prominence at an increasing rate, are designed to actively involve citizens in "collecting, generating, and analysing data" (Illingworth and Allen, 2016, 5-12). These encounters allow citizens to gather knowledge or data that would be impossible to collect on their own in terms of quantity and accessibility. A citizen science project measuring exposure to the Deepwater oil spill had citizens contributing with information of what they saw and smelt. This project explains how an aggregation of citizens can detect "a broader range of impacts", such as "smells, smoke, and other potential risk factors", and these data may then be employed to "shape the conduct of political decision-making and/or the development of expert science" (McCormick, 2012). Another relevant example is the Air Quality Egg project, in which citizens - using an egg-shaped device - measure air pollution levels in their surroundings, upload them to the internet, and compare pollution levels recorded by other eggs elsewhere. The Air Quality Egg project is a communityled initiative that facilitates participation in the conversation about air quality (Muller et al., 2015).

Thirdly, this dialogical approach found in citizen science initiatives, and in citizen participation in a broader sense, raises the levels of awareness of, and engagement in, air pollution reduction of the people involved. For instance, a project involving citizens in air monitoring campaigns in four European cities (Antwerp, Kassel, London, and Turin), concludes that "the most effective way of producing a change is involving the citizens themselves in monitoring campaigns" (Sîrbu et al., 2015). A different example in Kenya, involving women in air pollution measurements and further discussion with experts, also concludes that "participation in conducting and interpreting air quality studies helped residents improve their understanding of air pollution and also helped them develop responses to it" (Ngo et al., 2017, p. 177). A reduction in the discrepancy between real and perceive levels of air pollution after participating in monitoring campaigns, as well as a more accurate identification of air pollution sources are some examples of the ways in which active participation is able to change levels of awareness (e.g. Ngo et al., 2017; Sîrbu et al., 2015). Examples of behavioural change as a result of active participation are different actions in which res- idents get involved to reduce the impacts that air pollution causes to them and their communities, such as planting trees, avoiding pollution areas or sources, or switching to clean cook stoves (e.g. Ngo et al., 2017). The positive outcomes of citizen science, and citizen participation more broadly, have been attributed to the capacity to promote place-based learning. This means that individuals are able to relate scientific information to their communities, making it more comprehensible and relevant (Groulx et al., 2017). Additionally, participants develop stronger ties to their surrounding environment, which is in turn translated into a more intense feeling of caring about an issue, such as clean air for their community. Furthermore, participants also create social bonds with experts, and other people in their community, which then results in more regular participation and more meaningful involvement with an issue (Groulx et al., 2017).

Fourthly, two-way communication can help provide a better emergency response to an air pollution crisis. In such a crisis, like the Southeast Asian Haze in 2013, both experts and affected populations have valuable information that can help provide a more accurate response. If the experts can send out warnings and information on how to behave that are valuable to the public and will improve their course of action (e.g. staying indoors or limiting outdoor physical activity), citizens can contribute with on-the-ground experiences or information about their physical and psychological wellbeing. As explained in the Southeast Asian Haze example, this "is important in assessing how the population is coping and responding thus far to the crisis" and in providing better support tailored to that information (Zhang et al., 2014).

Fifthly, two-way communication can improve trust between citizens and professionals working with air pollution. On some occasions, when experts and the public work sideby-side, either in citizen science projects or in deliberative encounters, they inevitably increase their levels of trust in one another, which in turn encourages further dialogue and more effective communication in general. As trust, after all, is about being able to relate to the other person (Corner et al., 2018). A community forum organized in Kenya to discuss air quality and its health impacts, concluded that "involving local people and discussing the scientific data, as opposed to simply reporting measurements done by academics alone, helped generate trust" (Ngo et al., 2017, p. 181). In other words, if it is commonplace that citizens tend to question the interests of governments in relation to air pollution and environmental management, the climate of distrust is more prominent in those segments of the population that are more economically and socially disadvantaged and that are more disconnected from the decision-making process. This reinforces the fact that proximity and dialogue between these two groups can be understood as trust restorative tools (Bickerstaff, 2004; Walker et al., 1998).

Two-way communication in relation to air pollution risk can take many shapes as it is being carried out through multiple innovative formats. Social media, for instance, can be 
used in relation to an incident, such as the aforementioned air pollution crisis (e.g. Zhang et al., 2014), as well as to raise awareness and discuss what measures individuals can implement in their day-to-day activities (e.g. Kay et al., 2015). The effectiveness of social media relies, on the one hand, on that it allows dealing with the immediacy coupled to a crisis event; and on the other hand, on the horizontal lines of interaction between members of the public encouraging different voices to be heard. Educational programmes and serious games, for example, can also be employed to raise awareness of how our actions are contributing to air pollution and what adaptation and mitigation behaviours are already available, as well as to foster more technical knowledge, such as deeper understanding of city development problems leading to pollution. The effectiveness of these two formats relies on the binomial fun and knowledge combination, which is often achieved by incorporating gamification elements, rich visualizations, or hands-on activities. Citizen science initiatives too can contribute to increasing levels of awareness. The effectiveness of this format relies on active learning and on having hands-on activities, such as the aforementioned case in which participants were involved in taking measurements of personal exposures to air pollution. In turn, the large amount of data recorded by multiple individuals in citizens science initiatives, contributes to advancing knowledge as this data could otherwise not be collected by experts alone (e.g. Sîrbu et al., 2015). Discussion forums - in which experts and citizens meet face-to-face and spend extended periods of time discussing an issue in-depth - can be employed for them to work together towards the formation of policies, as well as to develop scientific and technological expert knowledge that, by exploring and integrating local and experiential knowledge, becomes more relevant at the local scale (e.g. Whatmore and Landström, 2011). Finally, poetry can be employed to foster positive change at the community level, to facilitate discussion between experts and the public, and most importantly, to invite communities that often find themselves neglected to participate in dialogues and debates about issues such as air pollution (Illingworth and Jack, 2018). The intrinsic characteristics of these formats show that the different benefits or outcomes obtained from two-way communication appear to be tied to specific communication formats.

Two-way communication varies in the degree of engagement and bidirectionality it allows, as well as in how much control are experts willing to cede. The varying degrees of engagement have been explained with the metaphor of a ladder (Arnstein, 1969) from lower rungs aiming at mining citizens' knowledge, to higher rungs granting citizen control. Engagement will not always be an equal partnership in which the public is involved from the early stages, is encouraged to deliberate jointly with the experts, in which both agendas are pushed equally, and there is the goal of reaching consensus. This would be the ultimate form of engagement aiming to "improve the quality of decision-making, to create more socially robust scientific and technological solutions" (Wils- don and Willis, 2004, p. 39). Sometimes these dialogues may only seek citizens' opinions and explore different views of, for instance, a new technology or a new policy. Although this latter form of dialogue - which has been subject to criticism - is less than optimal as it can be seen as an appeasement (Arnstein, 1969), or as an instrument of governments and companies to be able to "sell" their developments and policies better (Wilsdon and Willis, 2004), it can also be seen as a step closer to citizen participation in which individuals and their environments are explored and taken into consideration.

\section{Conclusion}

In order to maximize the chances of communication of hazards in general and of air pollution in particular being effective in fostering more aware and engaged citizens, communication must go beyond a one-way provision of information. Effective communication requires consideration of the amount of information that is necessary, as well as the language and framing of the message itself, all of which are subject to individual differences. It has to explore the inner world of the individual, as well as the environment in which it is embedded. Additionally, communication needs to overcome trust issues. A dialogical approach offers the opportunity and mechanism to do this, and it is therefore much more likely to be both effective and efficient.

We suggest here that air pollution experts should consider two-way forms of communication and explore the benefits that a dialogical approach can offer. For a scientist, a policymaker, or a member of the emergency services, engaging with citizens can translate into more relevant and robust outcomes, whether these are scientific advancements, technologies, policies, or crisis responses.

Two-way communication in relation to air pollution has (at least) five benefits: (i) it can facilitate the formation of policies, as well as scientific and technological developments that are more relevant for society; (ii) it can help complement data gathered by experts; (iii) it can improve societal awareness and encourage necessary protective and mitigation behaviour; (iv) it can offer a more accurate response to a crisis; and finally, (v) it can improve levels of trust between public and experts. All of these benefits are essential if the air pollution challenge faced locally and globally today are to be successfully tackled.

Despite the clear benefits, effective two-way communication is a challenge and there are still important questions to be addressed. Further research should have a greater focus on processes - rather than outcomes. That is, on understanding how positive experiences can be granted for everybody involved so that participation and dialogue are seen as something enjoyable and worth devoting time to. In relation to this, further research should also investigate how experts as well as members of the public can engage in these timeconsuming initiatives when they are already faced with too 
many demands on their time. Finally, further research should also explore if, and how, these encounters are developed differently when they are initiated by experts or by members of the public, and how their status, priorities, knowledge, etc. impose on the dynamics and dialogues these encounters elicit.

Data availability. No data sets were used in this article.

Competing interests. The authors declare that they have no conflict of interest.

Special issue statement. This article is part of the special issue "17th EMS Annual Meeting: European Conference for Applied Meteorology and Climatology 2017". It is a result of the EMS Annual Meeting: European Conference for Applied Meteorology and Climatology 2017, Dublin, Ireland, 4-8 September 2017.

Acknowledgements. The authors would like to thank the reviewers for their comments and insights while preparing this manuscript.

Edited by: Rebecca Hemingway

Reviewed by: Niki Harré and one anonymous referee

\section{References}

Arnstein, S. R.: A Ladder of Citizen Participation, J. American Inst. Plan., 35, 216-224, https://doi.org/10.1007/978-94-007-13215_10, 1969 .

Bickerstaff, K.: Risk perception research: socio-cultural perspectives on the public experience of air pollution, Environ. Int., 30, 827-840, https://doi.org/10.1016/j.envint.2003.12.001, 2004.

Bickerstaff, K. and Walker, G.: Public understandings of air pollution: the 'localisation' of environmental risk, Global Environ. Change, 11, 133-145, https://doi.org/10.1016/S09593780(00)00063-7, 2001.

Bowater, L. and Yeoman, K.: Science Communication: A Practical Guide for Scientists, 1st Edn., Wiley-Blackwell, Chichester, 2012.

Bultitude, K.: The Why and How of Science Communication, edited by: Rosulek, P., Science Commun. Eur. Comm., Pilsen, 2011.

Burningham, K., Fielding, J., and Thrush, D.: 'It'll never happen to me': understanding public awareness of local flood risk, Disasters, 32, 216-238, https://doi.org/10.1111/j.14677717.2007.01036.x, 2008.

Cacciatore, M. A., Scheufele, D. A., and Iyengar, S.: The End of Framing as we Know it ... and the Future of Media Effects, Mass Commun. Soc., 19, 7-23, https://doi.org/10.1080/15205436.2015.1068811, 2016.

Corner, A., Shaw, C., and Clarke, J.: Principles for effective communication and public engagement on climate change: A Handbook for IPCC authors, available at: https://climateoutreach. org/resources/ipcc-communications-handbook/ (last access: 3 February 2018), 2018.

Festinger, L.: A Theory of Cognitive Dissonance, Stanford University Press., Stanford, 1962.

Goodwin, J. and Dahlstrom, M. F.: Communication strategies for earning trust in climate change debates, Wiley Interdiscip. Rev. Clim. Change, 5, 151-160, https://doi.org/10.1002/wcc.262, 2014.

Groulx, M., Brisbois, M. C., Lemieux, C. J., Winegardner, A., and Fishback, L.: A Role for Nature-Based Citizen Science in Promoting Individual and Collective Climate Change Action? A Systematic Review of Learning Outcomes, Sci. Commun., 39, 45-76, https://doi.org/10.1177/1075547016688324, 2017.

Harre, D. N.: Psychology for a Better World: Strategies to Inspire Sustainability, University of Auckland, Department of Psychology, Auckland, NZ, 2011.

Illingworth, S. and Allen, G.: Effective Science Communication A practical guide to surviving as a scientist, IOP Publishing, Bristol, England, 2016.

Illingworth, S. and Jack, K.: Rhyme and reason-using poetry to talk to underserved audiences about environmental change, Clim. Risk Manage., 19, 120-129, https://doi.org/10.1016/j.crm.2018.01.001, 2018.

ISO 31000:2018: Risk management - Principles and guidelines, International Organization for Standardization, Geneva, Switzerland, 2018.

Kay, S., Zhao, B., and Sui, D.: Can Social Media Clear the Air? A Case Study of the Air Pollution Problem in Chinese Cities, Prof. Geogr., 67, 351-363, https://doi.org/10.1080/00330124.2014.970838, 2015.

Lo, A. Y., Alexander, K. S., Proctor, W., and Ryan, A.: Reciprocity as deliberative capacity: Lessons from a citizen's deliberation on carbon pricing mechanisms in Australia, Environ. Plan. C, 31, 444-459, https://doi.org/10.1068/c11192, 2013.

Longnecker, N.: An integrated model of science communication More than providing evidence, J. Sci. Commun., 15, Y01, 2016.

Lorenzoni, I., Nicholson-Cole, S., and Whitmarsh, L.: Barriers perceived to engaging with climate change among the UK public and their policy implications, Global Environ. Change, 17, 445459, https://doi.org/10.1016/j.gloenvcha.2007.01.004, 2007.

McCormick, S.: After the cap: Risk assessment, citizen science and disaster recovery, Ecol. Soc., 17, 31, https://doi.org/10.5751/ES05263-170431, 2012.

Miller, S.: Public understanding of science at the crossroads, Publ. Underst. Sci., 10, 115-120, https://doi.org/10.1088/09636625/10/1/308, 2001

Muller, C. 1., Chapman, L., Johnston, S., Kidd, C., Illingworth, S., Foody, G., Overeem, A., and Leigh, R. r.: Crowdsourcing for climate and atmospheric sciences: current status and future potential, Int. J. Climatol., 35, 3185-3203, https://doi.org/10.1002/joc.4210, 2015.

Ngo, N. S., Kokoyo, S., and Klopp, J.: Why participation matters for air quality studies: risk perceptions, understandings of air pollution and mobilization in a poor neighborhood in Nairobi, Kenya, Public Health, 142, 177-185, https://doi.org/10.1016/j.puhe.2015.07.014, 2017.

Priest, S.: Communicating Climate Change - The Path Forward, edited by: Priest, S. and Macmillan, P., available at: 
http://www.palgrave.com/gp/book/9781137585783 (last access: 24 January 2018), 2016.

Rogers, E. M.: Diffusion of Innovations, 5th Edn., Free Press, New York, London, Toronto, Sydney, 2003.

Shannon, C. E. and Weaver, W.: The Mathematical Theory of Communication, University of Illinois Press, Urbana, 1998.

Sîrbu, A., Becker, M., Caminiti, S., De Baets, B., Elen, B., Francis, L., Gravino, P., Hotho, A., Ingarra, S., Loreto, V., Molino, A., Mueller, J., Peters, J., Ricchiuti, F., Saracino, F., Servedio, V. D. P., Stumme, G., Theunis, J., Tria, F., and Van Den Bossche, J.: Participatory patterns in an international air quality monitoring initiative, Plos One, 10, e0136763, https://doi.org/10.1371/journal.pone.0136763, 2015.

Walker, G., Simmons, P., Irwin, A., and Wynne, B.: Public Perception of Risks Associated with Major Accident Hazards, HSE Books, available at: https://ueaeprints.uea.ac.uk/49377/ (last access: 2 February 2018), 1998.
Whatmore, S. J. and Landström, C.: Flood apprentices: an exercise in making things public, Econ. Soc., 40, 582-610, https://doi.org/10.1080/03085147.2011.602540, 2011.

WHO - World Health Organization: WHO releases country estimates on air pollution exposure and health impact, available at: http://www.who.int/mediacentre/news/releases/2016/ air-pollution-estimates/en/ (last access: 19 December 2017), 2016.

Wilsdon, J. and Willis, R.: See-through science: why public engagement needs to move upstream, Demos, London, 2004.

Xu, J., Chi, C. S. F., and Zhu, K.: Concern or apathy: the attitude of the public toward urban air pollution, J. Risk Res., 20, 482-498, https://doi.org/10.1080/13669877.2015.1071869, 2017.

Zhang, M. W. B., Ho, C. S. H., Fang, P., Lu, Y., and Ho, R. C. M.: Usage of social media and smartphone application in assessment of physical and psychological well-being of individuals in times of a major air pollution crisis, J. Med. Internet Res., 2, e16, https://doi.org/10.2196/mhealth.2827, 2014. 